\title{
Electrocardiographic changes resembling myocardial ischaemia in asymptomatic men with normal coronary arteriograms
}

PETER TAGGART, MALCOLM CARRUTHERS, SIMON JOSEPH, H. B. KELLY, J. MARCOMICHELAKIS, DENIS NOBLE, G. O'NEILL, AND WALTER SOMERVILLE

From the Department of Cardiology, The Middlesex Hospital, London; the Department of Chemical Pathology, St Mary's Hospital, London; the Central Medical Establishment, Royal Air Force; and University Laboratory of Physiology, Oxford

SUMMARY $T$ wave and ST segment abnormalities in 20 asymptomatic men aged 18 to 55 were investigated because they were identical with myocardial ischaemic changes, and the professional livelihood of the subjects was jeopardised.

Coronary arteriograms showed unobstructed arteries in all except one in whom a 50 per cent lesion of the left anterior descending artery was present. Left ventricular angiograms showed a normal contraction pattern. Ejection fractions were normal in 12 and increased in 8.

Three characteristic electrocardiographic patterns were observed: flat or inverted $\mathrm{T}$ waves in leads II, III, aVF, and V4 to 6 designated type 1; deep T inversion particularly evident in leads V2 to 5 designated type 2, and minor ST segment depression in the inferior and lateral leads without $\mathrm{T}$ changes designated type 3.

Characteristically, type 1 changes were temporarily suppressed by either beta-blockade or an overnight rest and were more abnormal in the standing position. Type 2 and 3 changes were relatively uninfluenced by these manoeuvres.

Maximal treadmill exercise tests were positive in 6 and borderline or negative in 14. When repeated after oxprenolol all tests were negative.

Echocardiograms showed asymmetric septal hypertrophy in 3 subjects (ratio of greater than 1.5 between ventricular septum and posterior left ventricular wall).

After normalisation by an overnight rest, type $1 \mathrm{~T}$ wave abnormalities were reproduced by intravenous adrenaline infusion $(0.024$ to $0.18 \mu \mathrm{g} / \mathrm{kg} / \mathrm{min})$ but not by noradrenaline or by adrenaline after prior administration of oxprenolol. When the $\mathrm{T}$ waves had remained deeply inverted before infusion despite rest (type 2) adrenaline infusion normalised them and again noradrenaline was without effect. This effect was also prevented by oxprenolol. Type 3 changes were uninfluenced by catecholamine infusion.

Plasma catecholamine estimations suggest that catecholamine hypersecretion and hypersensitivity may both be relevant, particularly the latter.

The apparent bimodal response of the ventricular myocardium to adrenaline infusion is not surprising since in vitro experiments suggest that reversal of $\mathrm{T}$ wave polarity in either direction may result from summation of changes in action potential duration in different parts of the heart. Such changes may be unimodal, that is both areas involved show lengthening or shortening of action potential duration, but by occurring at different rates may lead to a bimodal change in the differences in duration which generate the $\mathrm{T}$ wave.

The finding of $T$ wave and ST segment abnormalities identical with myocardial ischaemic

Received for publication 4 April 1978 changes in routine electrocardiograms of asymptomatic and apparently healthy people presents a difficult medical and socioeconomic problem. For example, periodic electrocardiograms are a man- 
Table 1 Routine electrocardiographic findings in RAF aircrew 1972-1975

\begin{tabular}{|c|c|c|c|c|}
\hline Findings & $\begin{array}{l}\text { No. of } \\
\text { ECGs }\end{array}$ & $\%$ Total & $\begin{array}{l}\text { No. of } \\
\text { men }\end{array}$ & $\%$ Total \\
\hline $\begin{array}{l}\text { ST and T changes } \\
\text { Incomplete RBBB } \\
\text { Arrhythmias } \\
\text { LAD beyond }-30^{\circ} \\
\text { Complete BBB (R and L) } \\
\text { Proven coronary disease } \\
\text { Heart block } \\
\text { WPW } \\
\text { Viral myocarditis } \\
\text { 'Miscellaneous' } \\
\text { Normal }\end{array}$ & $\begin{array}{r}416 \\
241 \\
98 \\
87 \\
59 \\
21 \\
16 \\
15 \\
9 \\
79 \\
12253\end{array}$ & $\begin{array}{r}3 \cdot 1 \\
1 \cdot 8 \\
0 \cdot 7 \\
0.7 \\
0.4 \\
0.2 \\
0 \cdot 1 \\
0 \cdot 1 \\
0 \cdot 1 \\
0.6 \\
92 \cdot 2\end{array}$ & $\begin{array}{r}338 \\
226 \\
89 \\
71 \\
35 \\
14 \\
14 \\
12 \\
2 \\
63 \\
7761\end{array}$ & $\begin{array}{l}3 \cdot 9 \\
2 \cdot 6 \\
1 \cdot 0 \\
0 \cdot 8 \\
0 \cdot 4 \\
0 \cdot 2 \\
0 \cdot 2 \\
0 \cdot 1 \\
0 \\
0 \cdot 8 \\
90 \cdot 0\end{array}$ \\
\hline Total & 13294 & $100 \cdot 0$ & 8625 & $100 \cdot 0$ \\
\hline
\end{tabular}

RBBB, right bundle-branch block; LAD, left axis deviation; WPW, Wolf-Parkinson-White syndrome.

datory requirement in pilots and personnel of allied occupations such as air traffic control officers (ATCO). Abnormalities of repolarisation are the commonest anomalies and the recent Bethesda conference on 'Cardiovascular problems associated with aviation safety' (American College of Cardiology, 1975) highlights current concern and controversy about interpretation and management.

In the 4 years 1972 to 197513294 routine electrocardiograms were carried out on 8625 individual RAF aircrew. A crude breakdown is shown in Table 1 from which it will be seen that 416 electrocardiograms on 338 of the men showed repolarisation changes at rest, that is 3.1 per cent of all the electrocardiograms and 3.9 per cent of the men had ST-T changes constituting 40 per cent of all the recorded abnormalities. It was particularly apparent that a considerable number of these were in young asymptomatic individuals who seemed unlikely to have significant coronary heart disease, cardiomyopathy, or other important disease. Of electrocardiograms recorded from 5217 civil professional aircrew and ATCOs between September 1974 and December 1975, $202(3.9 \%)$ showed ST-T abnormalities (Joy, 1977).

$\mathrm{T}$ and ST abnormalities in the apparent absence of disease are well known to occur and have been variously attributed to a wide variety of causes including emotion (Taggart et al., 1978), neurocirculatory asthenia (Holmgren et al., 1959), the hyperkinetic heart syndrome (Guazzi et al., 1975), posture (Mayerson and Davis, 1942), and hyperventilation (Kemp and Ellestad, 1968).

Our previous studies on the effects of emotions of different types and intensities including driving in city traffic (Taggart et al., 1969), speaking before an audience (Taggart et al., 1973), racing car driving (Taggart et al., 1969), and parachute jumping (Taggart et al., 1974) have shown an increased plasma catecholamine concentration associated with ST-T changes in young, fit adults, suggesting a possible cause and effect relation. This contention receives support from observations showing that beta-blockade may prevent or at least minimise such electrocardiographic abnormalities in response to emotion (Taggart et al., 1973), the hyperkinetic heart syndrome (Guazzi et al., 1975), posture (Kattus et al., 1970), and hyperventilation (Furberg and Tengblad, 1966). However probable that such changes are caused by variations in autonomic activity/response, nevertheless their similarity to those associated with myocardial ischaemia remains irrefutable.

Maximal treadmill exercise testing rather than clarifying may, in some patients, compound the problem. Though achieving a 60 to 70 per cent sensitivity, this test suffers the important limitations imposed by its roughly 90 per cent specificity.

Consequently the state of the coronary arteries has often to be decided by coronary arteriography. Though the demonstration of normal coronary arteries is sufficient to satisfy certain licensing bodies (American College of Cardiology, 1975), uncertainties as to prognosis remain in view of the lack of understanding of the pathophysiology involved. For this reason, in the course of routine investigation of such patients we have included observations on intravenous infusion of adrenaline and noradrenaline with and without beta-adrenergic blockade.

We present now observations on 20 asymptomatic men referred consecutively for investigation of $\mathrm{T}$ and ST abnormalities and whose licence or livelihood was jeopardised. All had normal coronary arteriograms except a 55-year-old man with an isolated 50 per cent lesion of the left anterior descending coronary artery.

\section{Subjects and methods}

Studies were made of 20 male subjects aged 18 to 55 (mean 34). Of these, 10 were qualified pilots of varying experience, 3 were applicants for training, 2 were air traffic control officers, 2 were army ground personnel, 1 was an air commodore, 1 was an RAF navigator, and 1 was an RAF air engineer who wished to become a flight engineer. All were asymptomatic and physical examination disclosed nothing more than mild hypertension in $\mathbf{4}$ for which one (case 18) had been taking chlorthalidone. Nine were regularly engaged in athletic activities which in 4 were of exceptional standard. Eighteen had been referred because of an abnormal routine resting electrocardiogram. Two had previous nonspecific symptoms at which time an abnormal electrocardio- 
gram had been recorded; one of these persons is considered in detail (see below). The purpose of the observations was explained in detail to each subject.

\section{EXERCISE TESTING}

Maximal treadmill exercise tests were conducted using the multi-stage procedure derived by Doan et al. (1965). The end point chosen was the subject's limit of tolerance rather than target heart rates. The three-channel Avionics monitor model 3000 and computer programmer P.100 was used with the $\mathrm{CM}$ lead system. The 3 praecordial leads were positioned after inspection of the resting electrocardiograms of each subject in order to include those areas where maximum changes had been observed. CM5 was incorporated in each case.

Each subject underwent at least 2 tests, the first conducted without prior medication and the second after an oral dose of $80 \mathrm{mg}$ oxprenolol (Trasicor) administered $1 \frac{1}{2}$ hours previously. The following procedure was adopted. After 5 minutes of recumbent rest a blood sample was taken for plasma catecholamine estimations. Electrocardiograms were then made in the lying and standing position, during 20 seconds of hyperventilation, during the performance of the Valsalva manoeuvre, at the end of each stage of exercise, and at 1-minute intervals for 10 minutes in the recovery period monitored with the subject recumbent. A second blood sample for catecholamine estimations was taken in the recumbent position immediately on completion of exercise. Cuff blood pressure measurements were made at rest before exercise, 30 seconds before the end of each stage, and at minute intervals during the 10-minute period of recovery. In no instance was it necessary to terminate the test prematurely.

Tests were considered positive when ST segment depression of $1 \mathrm{~mm}$ or more, as compared with the control tracing, was observed in at least 6 consecutive beats, measured at 60 milliseconds after the nadir of the $S$ wave with reference to the $P R$ segment and irrespective of whether the ST segment was upsloping, horizontal, or downsloping. Inevitably when eyeballing analysis is employed there is a 'grey area of indecision' and such tests were classified as 'borderline'.

\section{BETA-BLOCKADE}

An oral dose of propranolol ( 20 to $40 \mathrm{mg}$ ) was given to 10 subjects outside hospital immediately after recording an abnormal electrocardiogram, and the tracing was repeated 1 to 2 hours later.

\section{ECHOCARDIOGRAMS}

Echocardiographic studies were carried out in all subjects in the supine position using a com- mercially available Echograph (Smith-Kline Ekoline $20 \mathrm{~A}$ ) and a $2.25 \mathrm{MHz}$ transducer focused at $7.5 \mathrm{~cm}$ and recording on a Cambridge strip chart recorder.

Mitral valve echoes were identified by placing the transducer in the $3 \mathrm{rd}$, 4 th, or 5 th intercostal space and directing the beam posteriorly or slightly medially. Aortic valve echoes were obtained by rotating the transducer medially and cephalad from the mitral valve position.

Interventricular septal echoes were recorded at two levels, that is at the mitral level (position 3) and at the submitral level when the ultrasonic beam was passing through the left ventricular cavity just past the tip of the mitral valve.

Free posterior left ventricular wall echoes were recorded at the submitral level (position 4) and measured in end-diastole.

Interventricular septal to posterior free ventricular wall thickness ratio was calculated and considered abnormal when exceeding 1.5 .

The left ventricular outflow tract width was measured at the mitral level (position 3) as the minimum distance between the closed position of the mitral valve (point 5) and the left side of the interventricular septum at the onset of systole.

In the mitral valve echograms we studied the behaviour of the mitral apparatus in systole; when the systolic anterior motion (SAM) was equivocal, incomplete, small, or inconstant, simple provocative tests using amyl nitrite inhalation were performed. We found the Valsalva manoeuvre of no help as a provocative test as it destroyed the quality of the echoes.

Aortic valve echoes were studied in particular for the character of cusp motion pattern and for evidence of mid-systolic closure.

\section{CARDIAC CATHETERISATION}

Left heart catheterisation and coronary arteriography using the Sones technique was carried out in all patients. Single plane left ventricular cineangiography was performed in the right anterior oblique position (RAO) at $30^{\circ}$ at 40 frames per second. Right heart catheterisation was also undertaken in 10 patients. Ejection fractions were calculated using the method of Sandler and Dodge (1968) modified for the right anterior oblique position.

\section{INFUSION OF CATECHOLAMINES}

Each subject received separate intravenous infusions of adrenaline, and then, after a half-hour interval, noradrenaline without any prior medication. The same infusion procedure was repeated $1 \frac{1}{2}$ hours after the oral administration of $80 \mathrm{mg}$ oxprenolol. Dilutions of adrenaline and noradrenaline were prepared 
in normal saline within 1 hour of the start of each infusion. The Harvard constant infusion pump (model 975) was used. Electrocardiograms were recorded on a three-channel Mingograph, the lead positions being selected as for the exercise tests.

A procedure was devised whereby each infusion included 4 different rates: $0.024 \mu \mathrm{g} / \mathrm{kg}$ per $\mathrm{min}$, $0.047 \mu \mathrm{g} / \mathrm{kg}$ per min, $0.091 \mu \mathrm{g} / \mathrm{kg}$ per min, and $0.18 \mu \mathrm{g} / \mathrm{kg}$ per min. Each infusion was continued for 4 minutes with an interval of 3 minutes or longer as necessary for the blood pressure to return to its control value. The procedure was terminated prematurely if subjective symptoms appeared or the blood pressure increased to more than $200 \mathrm{mmHg}$ systolic or $120 \mathrm{mmHg}$ diastolic. A dummy run was contrived in 6 subjects ( 4 group 1 and 2 group 2) by adjusting the pump to appear to be infusing but in fact not doing so.

In 5 subjects noradrenaline infusion was repeated after administration of atropine $1.2 \mathrm{mg}$ in order to assess whether baroreceptor reflex effects were relevant.

\section{PLASMA CATECHOLAMINE ESTIMATIONS}

Venous blood samples were collected for plasma catecholamine estimations immediately before exercise and at maximum exercise on both the tests with and without beta-blockade. Samples were processed and analysed by methods previously described (Carruthers et al., 1970).

\section{STATISTICAL ANALYSIS}

Plasma catecholamine concentrations being positively skewed, non-parametric statistics were employed. The Mann-Whitney U test was used to test the significance of the difference between medians of unpaired populations and the Wilcoxon signed rank test for paired populations.

Mean values with Student's t test were used for the other measurements.

\section{Results}

\section{RESTING ELECTROCARDIOGRAM}

Three electrocardiographic patterns, typical of those in the present study, are shown in Fig. 1. Low amplitude, flat, or inverted $T$ waves in the inferolateral leads (type 1 ) were present in 13 subjects, $T$ inversion confined to the septal leads was present in 4 (type 2), and ST segment depression (type 3) in 3.

\section{POSTURAL VARIATION}

Type 1 changes were more obvious when the subject was standing than when lying (Fig. 2). This postural effect was abolished by an oral dose of $80 \mathrm{mg}$
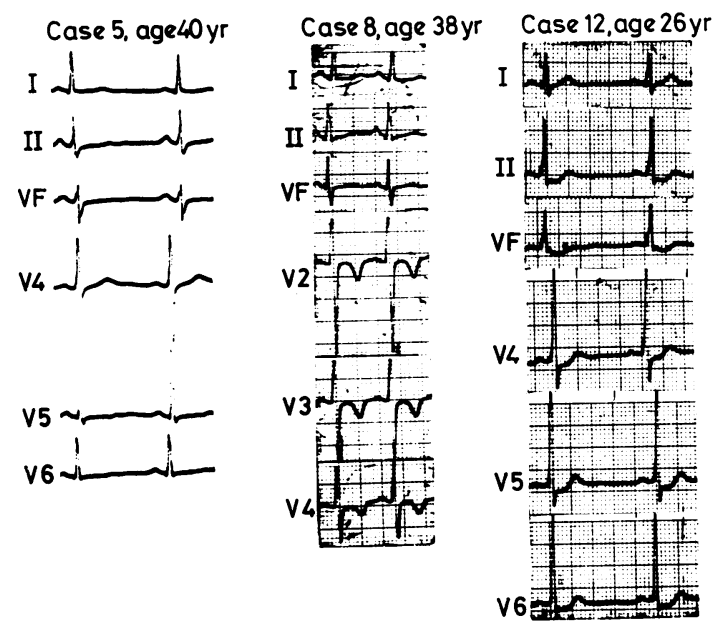

Fig. 1 Three typical electrocardiographic patterns designated for simplicity of discussion as type 1 (left), type 2 (centre), and type 3 (right).

oxprenolol. Type 2 and 3 changes were uninfluenced by body position.

\section{REST AND TRANQUILLITY}

Type 1 pattern was normalised either by an overnight rest in hospital or by beta-blockade in 9 and partially so in 4 (Fig. 3), types 2 and 3 retaining their 'abnormal' configuration.

\section{BETA-BLOCKADE}

After beta-blockade outside hospital, 7 type 1 subjects all reverted to normal whereas 2 type 2 and 1 type 3 were unchanged.

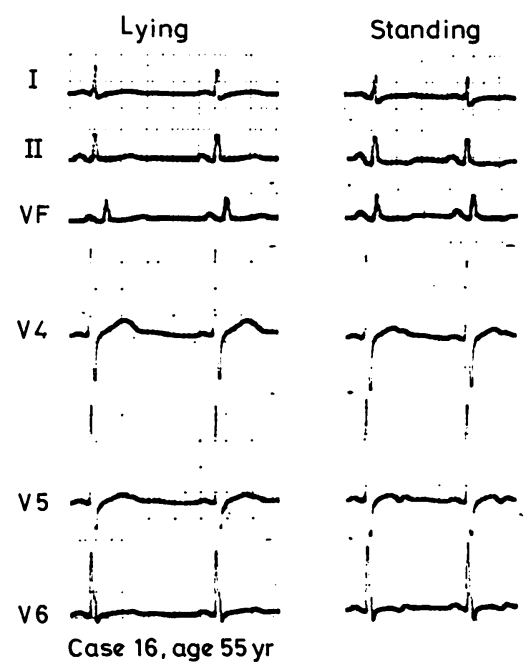

Fig. 2 Electrocardiographic abnormalities more obvious in the erect position in type 1. 


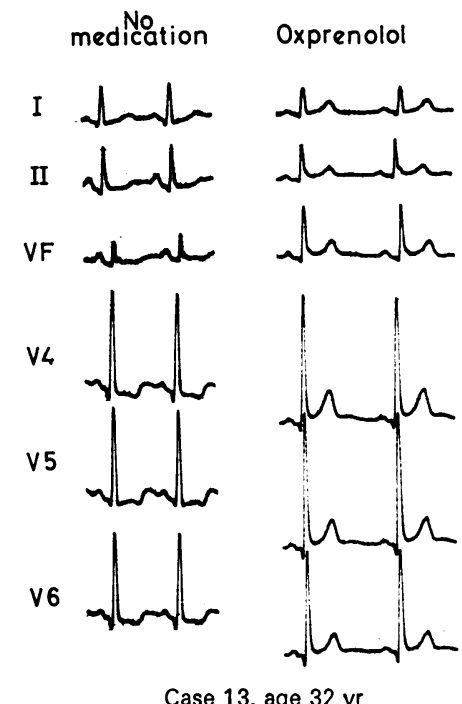

Fig. 3 Electrocardiographic abnormalities normalised by either an overnight rest or beta-blockade.

HYPERVENTILATION AND VALSALVA

Forced hyperventilation and the Valsalva manoeuvre produced variable and inconsistent effects.

\section{VACILLATION}

A feature of type 1 was a tendency to vacillate between upright and inverted $T$ waves. Electrocardiograms of a 39-year-old flight lieutenant (case 9) between the years of 1961 and 1975 are illustrated in Fig. 4. Four definite periods of $T$ wave abnormality were apparent, with intervening times when the $T$ waves were normal. $T$ wo weeks before the first abnormal electrocardiogram he had a febrile illness, and the $T$ wave abnormalities were attributed to viral myocarditis, and subsequent periods of $T$ wave inversion to recurrent attacks. He was asymptomatic throughout, an active sportsman with no abnormality on examination, chest $x$-ray, or biochemistry at any time, and was free of any coronary risk factors; the echocardiogram was normal.

\section{ECHOCARDIOGRAMS}

A septal to free posterior left ventricular wall ratio of greater than 1.5 was present in 3 subjects and of less than 1.5 in 17 (Table 2).

\section{EXERCISE TEST}

Maximum treadmill exercise tests without prior medication showed changes that would be classed as positive for myocardial ischaemia in 6 , borderline in 5, and negative in 9 (Fig. 5). After oxprenolol, no test was positive, 3 were borderline, and 17 were negative (Fig. 6) (Table 2). Heart rates in the unblocked tests increased from a mean value of 73 $( \pm 12.6 \mathrm{SD})$ at rest to $172( \pm 15.5)$ at maximum exercise and in the blocked tests from 64 $( \pm 8 \cdot 2)$ at rest to $119( \pm 21 \cdot 1)$ at maximum exercise. Heart rates were significantly lower in the blocked tests both at rest $(P<0.001)$ and at maximum exercise $(P<0.001)$. All but 3 subjects were unable to exercise for as long after oxprenolol. The mean times in minutes on the treadmill with and without medication, respectively, were $13.0( \pm 2.5 \mathrm{SD})$ and $14 \cdot 0$ ( $\pm 3 \cdot 3$ ). This difference fails to reach significance at the 5 per cent level for the group as a whole.
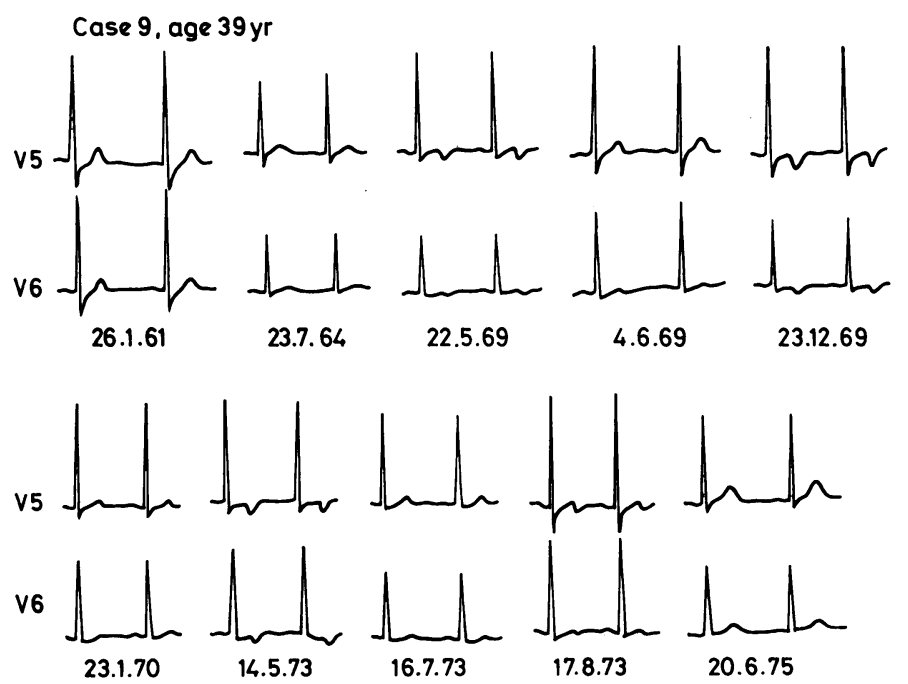

Fig. 4 Tendency to vacillate between normal and abnormal pattern, illustrated by case 9, aged 39. His age was 24 in 1961. 
Table 2 Individual data on 20 subjects in study

\begin{tabular}{|c|c|c|c|c|c|c|c|c|c|c|}
\hline \multirow{2}{*}{$\begin{array}{l}\text { Case } \\
\text { no. }\end{array}$} & \multirow[t]{2}{*}{ Age } & \multirow{2}{*}{$\begin{array}{l}\text { ECG } \\
\text { type }\end{array}$} & \multicolumn{3}{|c|}{ Echocardiograms } & \multicolumn{2}{|c|}{ Treadmill exercise ${ }^{\star}$} & \multicolumn{3}{|c|}{ Cardiac catheterisation $\uparrow$} \\
\hline & & & $\begin{array}{l}I V S \\
(m m)\end{array}$ & $\begin{array}{l}P L V W \\
(m m)\end{array}$ & $\begin{array}{l}\text { Ratio } \\
\text { (IVS/ } \\
\text { PLVW) }\end{array}$ & $\begin{array}{l}\text { No } \\
\text { medication }\end{array}$ & Oxprenolol & $R H C$ & LVEDP & $E F$ \\
\hline 1 & 23 & 1 & 11 & 9 & 1.22 & - & - & + & 12 & 0.73 \\
\hline 2 & 29 & 1 & 10 & 9 & $1 \cdot 11$ & - & - & + & 3 & 0.59 \\
\hline 3 & 30 & 1 & & & & - & - & - & 10 & 0.66 \\
\hline 4 & 38 & 2 & 14 & 8 & $1 \cdot 75$ & + & - & + & 12 & 0.76 \\
\hline 5 & 40 & 1 & & & & - & - & + & 11 & 0.75 \\
\hline 6 & 26 & 2 & 9 & 9 & 1.0 & B & - & + & 9 & 0.78 \\
\hline 7 & 38 & 1 & 10 & 9 & $1 \cdot 11$ & - & - & + & 10 & 0.69 \\
\hline 8 & 38 & 2 & 14 & 9 & 1.55 & - & - & + & 12 & 0.68 \\
\hline 9 & 39 & $\overrightarrow{1}$ & 12 & 9 & 1.33 & B & B & - & 15 & 0.77 \\
\hline 10 & 23 & 1 & 9 & 8 & $1 \cdot 12$ & + & - & + & 11 & 0.82 \\
\hline 11 & 21 & 1 & 8 & 8 & 1.0 & - & - & - & 7 & 0.95 \\
\hline 12 & 26 & 3 & 9 & 8 & $1 \cdot 12$ & + & - & + & 10 & 0.72 \\
\hline 13 & 32 & 1 & 11 & 9 & 1.22 & B & B & - & 9 & 0.72 \\
\hline 14 & 48 & 3 & 9 & 9 & 1.0 & + & B & - & 16 & 0.62 \\
\hline 15 & 35 & 2 & 9 & 8 & $1 \cdot 12$ & - & - & - & 5 & 0.71 \\
\hline 16 & 55 & 1 & 10 & 10 & 1.0 & + & - & + & 7 & 0.89 \\
\hline 17 & 41 & 1 & 18 & 9 & $2 \cdot 0$ & B & - & - & 5 & 0.75 \\
\hline 18 & 53 & 3 & 10 & 9 & $1 \cdot 11$ & + & - & + & 15 & 0.83 \\
\hline 19 & 43 & 1 & 10 & 8 & $1 \cdot 25$ & B & - & - & 5 & 0.84 \\
\hline 20 & 18 & 1 & 8 & 8 & 1.0 & - & - & - & 8 & 0.59 \\
\hline
\end{tabular}

IVS, intraventricular septal thickness; PLVW, posterior left ventricular wall thickness; * Treadmill tests: + a positive test; - a negative test; B, borderline result.

+ Cardiac catheterisation: RHC, right heart catheter, designated + or - to indicate whether included or not. LVEDP, left ventricular enddiastolic pressure; EF, ejection fraction.

No subject developed arrhythmia in any tests. Blood pressure response during and after the tests was normal in all subjects and did not suggest any impairment of left ventricular function.

\section{CARDIAC CATHETERISATION}

Of 20 subjects, 3 had a left ventricular end-diastolic pressure (LVEDP) above $12 \mathrm{mmHg}$ and an additional 3 showed raised values after left ventricular cineangiography. Right-sided pressures were normal in all 10 subjects in whom they were measured (Table 2).

Coronary arteriography was normal in all subjects except one (case 16) who had an isolated 50 per cent stenosis of the left anterior descending coronary artery. One other had an anomalous origin of a small circumflex vessel from the right coronary artery.

Mean left ventricular ejection fraction (LVEF) was $0.74( \pm 0.09 \mathrm{SD})$. In 12 subjects LVEF was in the normal range of 0.59 to 0.75 and in 8 it was increased, ranging from 0.76 to 0.95 (Table 2).
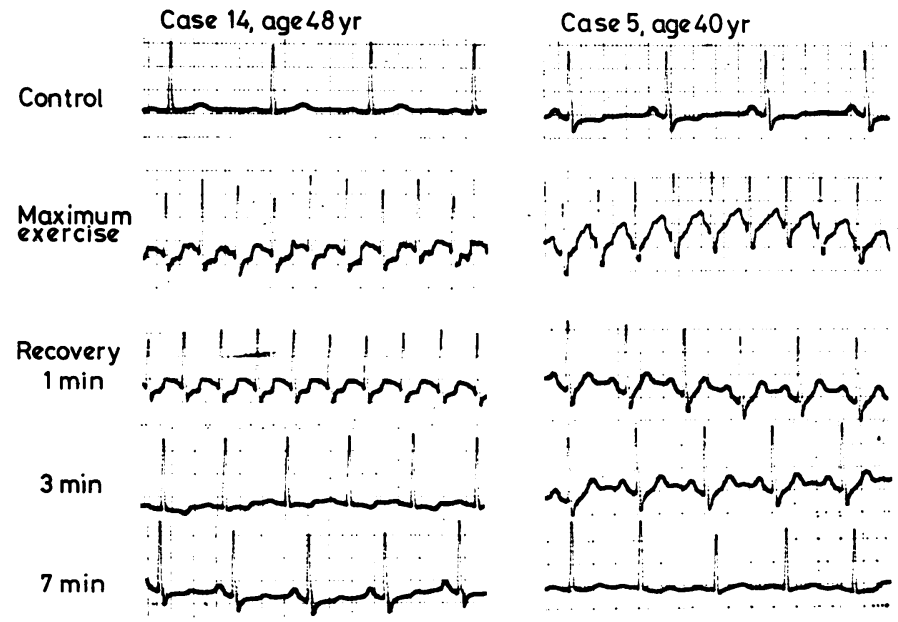

Fig. 5 Examples of a positive (left) and negative (right) maximum treadmill exercise test in different subjects without medication. 

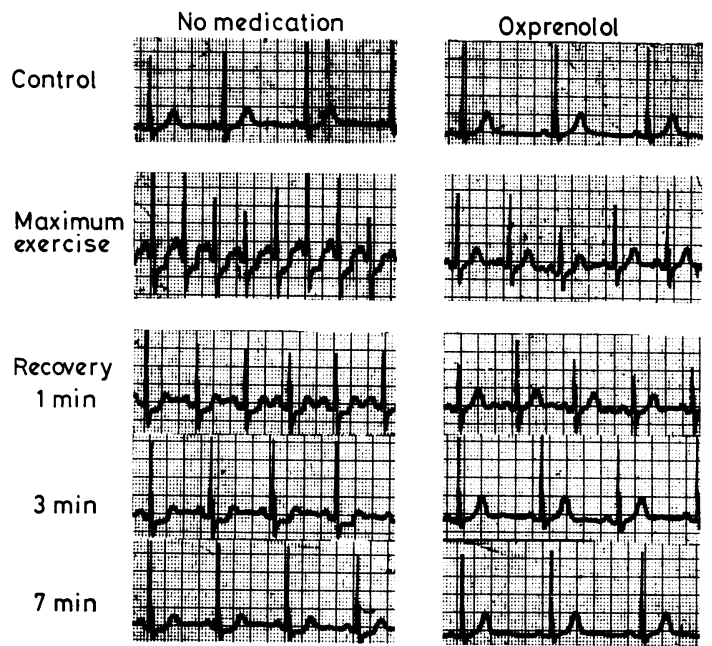

Case 18, age $53 \mathrm{yr}$

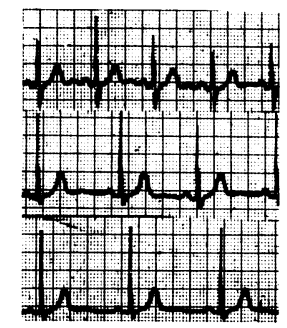

Fig. 6 Case 18, age 53-illustrating a positive maximum treadmill test (left) without medication and a negative test (right) after $80 \mathrm{mg}$ oxprenolol.

\section{INFUSION STUDIES}

\section{Adrenaline}

In subjects with type 1 changes on the resting electrocardiogram, in whom an overnight rest in hospital resulted in normalisation of the electrocardiogram, intravenous adrenaline infusion reproduced these abnormalities. The configuration of the reproduced changes was similar to the original abnormal pattern (Fig. 7). The tendency of this group to vacillate between normal and abnormal has been mentioned, and in those in whom a sufficient number of good quality previous electrocardiograms

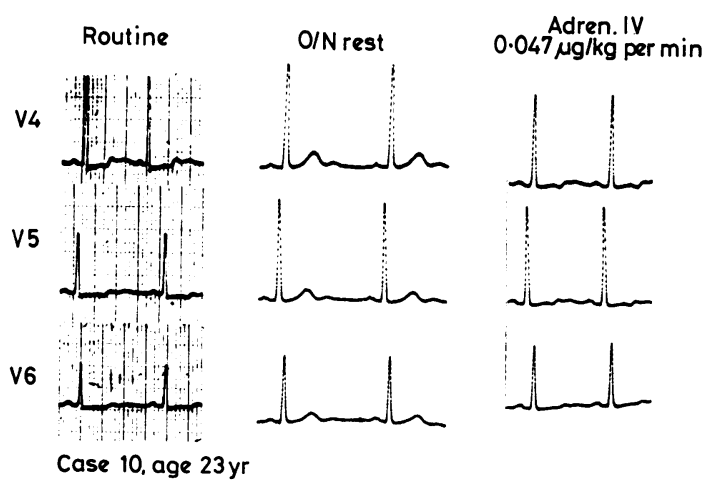

Fig. 7 Abnormal electrocardiographic pattern reproduced by intravenous infusion of adrenaline in case 1, age 23, whose electrocardiogram had become normalised by an overnight rest.

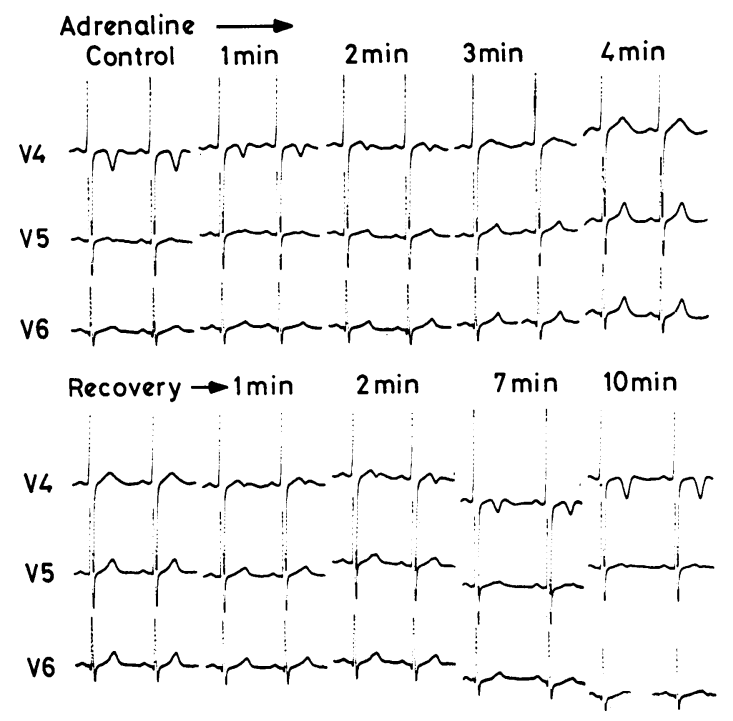

Case 8 , age 38 yr

Fig. 8 Normalisation of electrocardiogram by intravenous adrenaline in case 8 , age 38 , in whom an overnight rest did not correct the electrocardiogram, showing an effect opposite to that illustrated in Fig. 7.

was available, the intermediary patterns were seen to be mimicked by the evolutionary changes induced by adrenaline.

In subjects with type 2 changes in the resting electrocardiogram, in whom an overnight rest did not result in normalisation, intravenous adrenaline did so (Fig. 8), having seemingly the opposite effect to that seen in type 1 .

Neither the process of setting up the infusion nor the dummy run incorporated in 6 subjects ( 4 type 1 and 2 type 2 ) influenced the ST-T configuration.

In the 3 subjects with type 3 changes intravenous adrenaline appeared to be without effect on the ST segment or $\mathrm{T}$ wave.

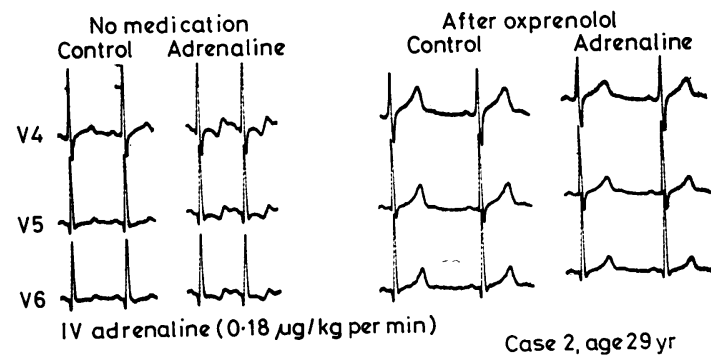

Fig. 9 Effect of intravenous adrenaline on electrocardiogram prevented by prior administration of oxprenolol. 
Adrenaline after beta-blockade

Adrenaline infusion when repeated using the identical procedure but performed $1 \frac{1}{2}$ hours after oxprenolol was completely without effect on the ST-T segment in all subjects (Fig. 9).

\section{Noradrenaline after beta-blockade}

Noradrenaline administered using the same dosage scheme was without influence on the electrocardiogram except for the predictable bradycardia associated with an increase in blood pressure.

A repeat infusion of noradrenaline after betablockade again did not influence the ST-T segment.

\section{Noradrenaline after atropine}

In the 5 subjects ( 3 type 1, 2 type 2 ) who received a repeat infusion of noradrenaline after intravenous atropine but without prior beta-blockade, no effect was observed on the electrocardiogram except for some degree of tachycardia.

\section{Plasma catecholamine concentrations}

Plasma catecholamine concentrations immediately before and at cessation of treadmill exercise testing are presented in Table 3A and confidence limits in Table 3B. Values for total catecholamines, noradrenaline, and adrenaline obtained before exercise

Table 3A Median plasma catecholamine concentrations $(\mu g / l)$ immediately before and at cessation of exercise in 20 subjects tested without prior medication (left) and after oxprenolol (right) ( $P$ derived by Wilcoxon signed rank test)

\begin{tabular}{|c|c|c|c|c|c|}
\hline \multirow[b]{2}{*}{ Total catecholamines } & \multirow[b]{2}{*}{ sefore } & \multicolumn{2}{|c|}{ No medication } & \multicolumn{2}{|c|}{ Oxprenolol } \\
\hline & & 0.8 & & & $\begin{array}{l}P \\
<0.01\end{array}$ \\
\hline & After & $1 \cdot 8$ & & 1.95 & \\
\hline \multirow[t]{2}{*}{ Noradrenaline } & Before & 0.6 & \multirow{2}{*}{$\begin{array}{l}\mathbf{P} \\
<0.01\end{array}$} & 0.55 & \multirow{2}{*}{$\begin{array}{l}\mathbf{P} \\
<0.01\end{array}$} \\
\hline & After & 1.35 & & $1 \cdot 6$ & \\
\hline \multirow[t]{2}{*}{ Adrenaline } & Before & $0 \cdot 1$ & \multirow{2}{*}{$\begin{array}{l}P \\
<0.01\end{array}$} & $0 \cdot 2$ & \multirow{2}{*}{$\begin{array}{l}P \\
<0.01\end{array}$} \\
\hline & After & 0.4 & & 0.4 & \\
\hline
\end{tabular}

Table 3B Confidence limits for median values in Table 3A

\begin{tabular}{ll}
\hline No medication & Oxprenolol \\
\hline $\mathbf{P}(0.6<0.8<1.2)=99.74$ & $\mathrm{P}(0.6<0.8<1.3)=99.74$ \\
$\mathbf{P}(1.0<1.8<3.2)=99.74$ & $\mathrm{P}(1.0<1.95<2.9)=99.74$ \\
$\mathbf{P}(0.4<0.6<0.9)=99.74$ & $\mathbf{P}(0.3<0.55<0.9)=99.74$ \\
$\mathbf{P}(0.6<1.35<2.8)=99.74$ & $\mathbf{P}(0.6<1.6<2.5)=99.74$ \\
$\mathbf{P}(0.1<0.1<0.4)=99.74$ & $\mathbf{P}(0.1<0.2<0.4)=99.74$ \\
$\mathbf{P}(0.1<0.4<0.5)=99.74$ & $\mathbf{P}(0.1<0.4<0.7)=99.74$
\end{tabular}

did not differ significantly from control subjects from whom samples were taken in tranquil conditions (Taggart, 1976). Both adrenaline and noradrenaline concentrations were increased at maximum exercise, these increases being comparable in both the tests with and without oxprenolol. There was no significant difference at the 95 per cent level between any of the respective unblocked and blocked values. Three individuals (2 type 1 and 1 type 3) showed exceptionally high noradrenaline concentrations in their post-exercise samples on both occasions.

\section{Discussion}

The diverse nature of the $T$ wave changes depicted in this study poses the question as to whether they represent totally unrelated pathological entities or merely an altered and variable physiological response. We would prefer the latter alternative since the $T$ changes may be linked together if we postulate a bimodal response to adrenaline. Our data may be conveniently represented according to the model in Fig. 10 whereby the $T$ wave is upright above a horizontal line, inverted below it, and adrenaline drives the curve to the right.

Testing this hypothesis, we may propose that those persons designated as having type 1 electrocardiographic abnormalities (Fig. 1) occupy position 1 (Fig. 10) when in a tranquil state. Any anxiety, such as that attendant on a medical examination, particularly if a licence and professional livelihood may be jeopardised, would be expected to move the electrocardiogram towards position 2 . Either the tranquillity of an overnight rest or beta-blockade would return the electrocardiogram to position 1 . The tendency to vacillation (Fig. 4) between upright and inverted $T$ waves so characteristic of type 1 changes is easy to understand on this basis. The fact that they become more obvious in the erect position (Fig. 2) may be because of increased sympathetic

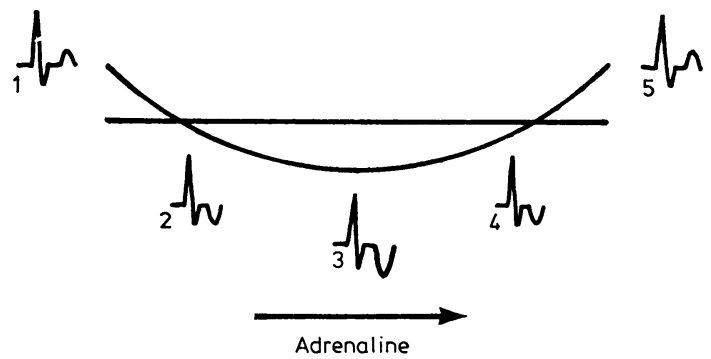

Fig. 10 Diagrammatic illustration of the bimodal response to adrenaline apparent from the data in this study. 
tone (Nordenfeld, 1965). Again, infusion of even a low dose of adrenaline after an overnight rest moves the electrocardiogram pattern from position 1 to 2 and this effect may be prevented by previous betaadrenergic blockade.

Those whose resting electrocardiograms occupy position 3 (type 2 ) would be unlikely to return to normal by tranquillity or beta-blockade as it would require the curve to be driven too far to the left. The small sympathetic discharge induced by posture would be insufficient to produce much, if any, discernible effect. Infusion of adrenaline, however, in a higher dosage should drive the curve to the right resulting in normalisation of the electrocardiogram at position 5 and subsequent return of the 'abnormal' pattern on recovery (Fig. 9). This effect should be prevented by beta-blockade, as was the case in our studies.

An unavoidable weakness of this study is the lack of control subjects. For obvious reasons it was considered inappropriate to conduct this series of tests in the absence of indisputable clinical indications. Lepeschkin et al. (1960) reported the effect of adrenaline and noradrenaline infusion on the electrocardiogram of 100 subjects with no clinically apparent heart disease, though coronary arteriography was not performed. Adrenaline infusion in doses 0.2 and $0.3 \mu \mathrm{g} / \mathrm{kg}$ per min produced $T$ inversion in the lateral praecordial leads in only 4 of 60 young women $(5.7 \%), 33$ of whom were pregnant, and infusion of $0.1 \mu \mathrm{g} / \mathrm{kg}$ per min produced similar changes in only 2 of $40(5 \%)$ young men, 20 of whom were active athletes. This contrasts with the present study in which $T$ inversion was produced in all 13 subjects with type 1 resting electrocardiographic abnormalities in whom infusion was started with a normal $T$ wave, in response to an infusion for similar length of time of up to $0.18 \mu \mathrm{g} / \mathrm{kg}$ per min. The 3 subjects with ST depression in their resting electrocardiogram at no time had $T$ wave inversion in routine recordings and the $T$ wave was uninfluenced by adrenaline.

Noradrenaline infusion resulted in a decrease in heart rate and either little change in, or a tendency to increase $\mathrm{T}$ wave amplitude, and was similar to the findings of Lepeschkin et al. (1960). The latter workers, however, attributed the difference between adrenaline and noradrenaline to reflex vagal excitation and sympathetic inhibition since after atropine noradrenaline behaved more like adrenaline. Other workers have reported the same phenomenon both in intact man (Littman et al., 1950) and in the isolated animal heart (Johansson and Vendsalu, 1957). In our studies the effect of noradrenaline was uninfluenced by atropine in the 5 subjects in whom this was included suggesting that the difference between the two hormones is at cellular level. That such a difference exists is supported by some animal studies (Giotti et al., 1973) and contradicted by others (Sparks et al., 1970).

It is appropriate to consider to what extent the diagrammatic representation of our data (Fig. 10) may be explained in physiological terms.

Bayliss and Starling (1892) first showed that the mammalian $\mathrm{T}$ wave might be attributed to differences in the duration of electrical excitation in different parts of the ventricle, and early work in this field (see Adrian et al., 1976, for references) strongly supported this view. The original arguments are carefully summarised by Mines (1913).

Subsequent argument has largely concerned the location of the relevant gradients of action potential duration and the cellular mechanism by which this gradient is generated. In isolated pieces of sheep ventricle, Cohen et al. (1976) showed that a duration gradient appears, as a consequence of repetitive activity, between tissue taken from the base of the septum and the epicardial surface of the apex. These experiments do not, however, distinguish between whether the gradient occurs between subepicardium and subendocardium (Gardberg and Rosen, 1957), between base and apex, or a number of other possibilities. Recent experiments by Kuo and Surawicz (1976) show that not all T wave changes are associated with changes in endocardial/epicardial gradients. They showed that reversal of $T$ wave polarity was, however, associated with changes in the difference between monophasic action potentials on the anterior and posterior ventricular walls.

In Fig. 11 and 12, we have labelled the two regions responsible for the duration difference relevant to the $T$ wave as area 1 (for example, endocardial septum) and area 2 (for example, epicardial apex) to avoid possible confusion with particular models of the $T$ wave. Their normal time relation to each other and to the electrocardiogram is shown in Fig. 11 (left). Any physiological event that causes area 2 to repolarise later than area 1 causes inversion of the $T$ wave (Fig. 11-centre).

The bimodal response to adrenaline proposed in Fig. 10 is illustrated in Fig. 11 in terms of action potential duration. In this instance it is assumed that whereas both action potentials (APs) are lengthened progressively there is an initial greater lengthening of area 2 action potential duration and subsequently a greater lengthening of area 1 action potential duration. There is conflicting evidence as to whether adrenaline shortens or lengthens the action potential duration. Under different conditions, catecholamines may do either (Giotti et al., 1973). However, whichever alternative is the case is immaterial. Hypothesis I supposes that adrenaline causes a 


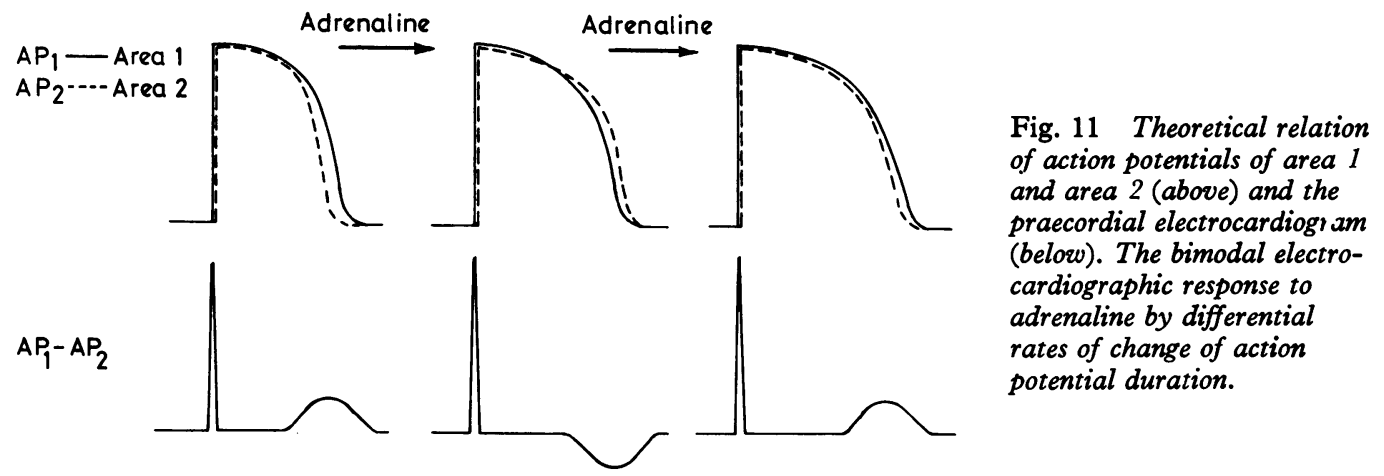

lengthening of both action potential groups but area 2 has a greater initial response but less ability to sustain it. Hypothesis II supposes that adrenaline causes a shortening of both action potential groups and that in this instance area 1 has a greater initial response but less ability to maintain it. By either of these means a unimodal change of action potential duration would result in a bimodal $T$ wave response to
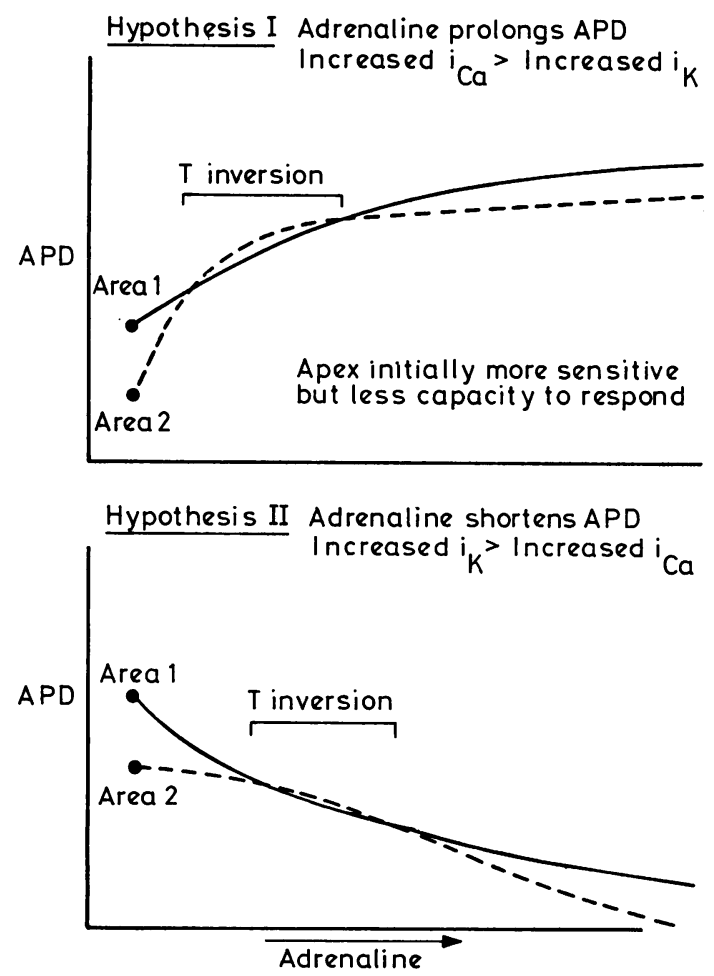

Fig. 12 Two hypotheses allowing a bimodal $T$ wave response irrespective of whether adrenaline results in lengthening or shortening of action potential duration. adrenaline. In this context it is interesting to note that Kuo and Surawicz (1976) have recently compared changes occurring after left stellate ganglion transection with those after right stellate ganglion stimulation. These procedures produced similar changes in $\mathrm{T}$ wave polarity despite the fact that the former prolonged and the latter shortened the QT interval.

Whatever the precise physiological mechanisms involved there is undoubtedly an unusual betareceptor responsiveness. It was to have been expected, therefore, that an incidence of false positive tests in excess of 10 per cent would be encountered in the subjects under discussion since a high incidence has been reported in people with normal coronary arteriograms and neurocirculatory asthenia (Murai, 1960), hyperventilation (Jacobs et al., 1974), and pronounced orthostatic changes (Kattus et al., 1970). All these are situations in which it has been suggested that an altered autonomic response is involved (Nordenfeld, 1965; Friesinger et al., 1972), a contention that receives support from the patients of Kattus et al. whose false positive tests were normalised after beta-blockade.

Reversal of functional electrocardiographic abnormalities by oral propranolol administered as a single dose (Noskowicz and Chrzanowski, 1968) or as a day course (Jackson, 1971) has been described. Coronary arteriograms were not performed on these patients. Considering the question as to whether beta-blockade may be useful as a test to differentiate functional from organic ST-T changes, Jackson points out that whereas organic ST changes were improved with propranolol they nevertheless remained abnormal. Furberg (1967) reviewing conflicting evidence concluded that ST-T changes associated with organic disease were not significantly altered by propranolol. The results of Prichard and Gillam (1971) accord more closely with Jackson (1971).

In certain persons, an electrocardiogram bearing 
a strong resemblance to myocardial ischaemia does not necessarily point to that diagnosis. Hence since they are not at hazard they should not have restrictions imposed upon them. However in pilots in whom sudden incapacitation may be disastrous, it would be premature to allow the issue or renewal of a licence in the presence of an abnormal electrocardiogram without coronary arteriography.

In the presence of unobstructed coronary arteries echocardiograms should be performed in order to detect 'silent' prolapsed mitral valve and asymmetric septal hypertrophy, since both are rare but real causes of collapse or sudden death. It seems hopeful that further studies along the lines of those presented here may facilitate the identification of this syndrome with sufficient clarity and confidence in order to rely on less invasive methods.

This study was financed by the Heart Research Fund of the Middlesex Hospital, CIBA Laboratories, and the Gallaher Charitable Foundation.

\section{References}

Adrian, R. H., Channell, R. C., Cohen, I., and Noble, D. (1976). The Einthoven string galvanometer and the interpretation of the $T$ wave of the electrocardiogram. Fournal of Physiology, 263, 67P-70P.

American College of Cardiology (1975). Cardiovascular problems associated with aviation safety. Eighth Bethesda Conference, April 25 and 26 1975, Washington, D.C. American fournal of Cardiology, 36, 573-628.

Bayliss, W. M., and Starling, E. H. (1892). On the electromotive phenomena of the mammalian heart. International Monatschrift für Anatomie und Physiologie, 9, 256-281.

Carruthers, M., Taggart, P., Conway, N., Bates, D., and Somerville, W. (1970). Validity of plasma catecholamine estimations. Lancet, 2, 62-67.

Cohen, I., Giles, W. R., and Noble, D. (1976). Cellular basis for the $T$ wave of the electrocardiogram. Nature, 262, 657-661.

Doan, A. G., Peterson, D. R., Blackmon, J. R., and Bruce, R. A. (1965). Myocardial ischaemia after maximal exercise in healthy men. A method of detecting potential coronary heart disease. American Heart fournal, 69, 11-21.

Friesinger, G. C., Biern, R. O., Likar, I., and Mason, R. E. (1972). Exercise electrocardiographic and vasoregulatory abnormalities. American fournal of Cardiology, 30, 733-740.

Furberg, C. (1967). Adrenergic beta-blockade and electrocardiographic ST-T changes. Acta Medica Scandinavica, 181, 21-32.

Furberg, C., and Tengblad, C. F. (1966). Adrenergic beta receptor blockade and the effect of hyperventilation on the electrocardiogram. Scandinavian fournal of Clinical and Laboratory Investigation, 18, 467-472.

Gardberg, M., and Rosen, I. L. (1957). The effects of nonpathologic factors on the electrocardiogram. II. Analysis. American Heart fournal, 53, 711-734.

Giotti, A., Ledda, F., and Mannaioni, P. F. (1973). Effects of noradrenaline and isoprenaline, in combination with alpha- and beta-receptor blocking substances, on the action potentials of cardiac Purkinje fibres. Fournal of Physiology, 229, 99-113.

Guazzi, M., Fiorentini, C., Polese, A., Magrini, F., and
Olivari, M. T. (1975). Stress-induced and sympatheticallymediated electrocardiographic and circulatory variations in $\stackrel{\vec{\rho}}{+}$ the primary hyperkinetic heart syndrome. Cardiovascular Research, 9, 342-354.

Holmgren, A., Johansson, B., Levander, M., Linderholm, H., Sjöstrand, T., and Ström, G. (1959). ECG changes in vasoregulatory asthenia and the effect of physical training. Acta Medica Sandinavica, 165, 259-271.

Jackson, W. B. (1971). The use of propranolol in ECG diagnosis. New Zealand Medical fournal, 73, 65-68.

Jacobs, W. F., Battle, W. E., and Ronan, J. A., Jr. (1974). False-positive ST-T wave changes secondary to exercise and hyperventilation. Annals of Internal Medicine, 81, 479-482.

Johansson, B., and Vendsalu, A. (1957). The influence of adrenaline, noradrenaline, and acetylcholine on the electro- $\nexists$ cardiogram of the isolated perfused guinea-pig heart. Acta iv Physiologica Scandinavica, 39, 356-369.

Joy, M. D. (1977). Contribution of resting electrocardiograph $\vec{A}$ to air transport safety (abstract). British Heart fournal, 39, 의 347.

Kattus, A. A., MacAlpin, R. N., and Alvaro, A. (1970). Reversibility of non-ischaemic postural and exercise induced ECG abnormalities of the $T$ wave and ST segments by beta-adrenergic blockade. In Cardiovascular Adrenergic Responses, UCLA Forum Series No. 13, p. 3. Ed. by A. A. Kattus, G. Ross, and V. E. Hall. University of California Press, Los Angeles.

Kemp, G. L., and Ellestad, M. H. (1968). The significance of hyperventilation and orthostatic $T$ wave changes on the electrocardiogram. Archives of Internal Medicine, 121, 518-523.

Kuo, C. S., and Surawicz, B. (1976). Ventricular monophasic action potential changes with neurogenic $T$ wave abnormalities and isoproterenol administration in dogs. American fournal of Cardiology, 38, 170-177.

Lepeschkin, E., Marchet, H., Schroeder, G., Wagner, R., $\overline{\bar{O}}$ Paula, E. De Paula e Silva, P., and Raab, W. (1960). Effect of epinephrine and norepinephrine on the electrocardiogram of 100 normal subjects. American fournal of Cardio $\log y, 5,594-603$.

Littman, A., Grossman, M. I., Gunnar, R. M., Isaacs, J. H., Hirschmann, J. H., and Foley, E. F. (1950). Electrocardiographic effects of arterenol and isopropylarterenol in man, with a note on the auricular $\mathrm{T}$ wave. Fournal of Applied Physiology, 3, 235-242.

Mayerson, H. S., and Davis, W. D., Jr. (1942). The influence 8 of posture on the electrocardiogram. American Heart fournal, 24, 593-601.

Mines, G. R. (1913). On functional analysis by the action of electrolytes. Fournal of Physiology, 46, 188-235.

Murai, A. (1960). The coronary insufficiency of neurogenic origin with special reference to neurocirculatory asthenia. $\mathrm{A}$ clinical study by means of exercise electrocardiograms. I. $\%$ Analysis of exercise responses. fapanese Circulation fournal, 24, 371-386.

Nordenfeld, O. (1965). Orthostatic ECG changes and the adrenergic beta-receptor blocking agent, propranolol (Inderal). Acta Medica Scandinavica, 178, 393-401.

Noskowicz, T., and Chrzanowski, W. (1968). The influence of propranolol on functional alterations of the electrocardio- $\mathbb{D}$ gram. Cardiologia, 52, 324-329.

Prichard, B. N. C., and Gillam, P. M. S. (1971). Assessment of propranolol in angina pectoris. British Heart fournal, 33, 473-480.

Sandler, H., and Dodge, H. T. (1968). The use of single plane $\cong$ angiocardiograms for the calculation of left ventricular $\unrhd$ volume in man. American Heart fournal, 75, 325-334.

Sparks, H. V., Jr., Hollenberg, M., Carriere, S., Funkenstein, D., Zakheim, R. M., and Barger, A. C. (1970). Sympatho- $\delta$ 
mimetic drugs and repolarization of ventricular myocardium in the dog. Cardiovascular Research, 4, 363-370.

Taggart, P. (1976). Some cardiovascular effects of the person's response to his emotional environment. M.D. Thesis, London.

Taggart, P., Carruthers, M., and Somerville, W. (1973). Electrocardiogram, plasma catecholamines and lipids and their modification by oxprenolol when speaking before an audience. Lancet, 2, 341-346.

Taggart, P., Carruthers, M. E., and Somerville, W. (1974). Cardiological aspects of beta-blockade in stress situations. In Beta-blockers-Present Status and Future Prospects, p. 173. Ed. by W. Schweizer. Hans Huber, Berne, Stuttgart, and Vienna.

Taggart, P., Carruthers, M., and Somerville, W. (1978). Emotions, catecholamines and the electrocardiogram. In Progress in Cardiology (In the press). Ed. by P. N. Yu andJ. F. Goodwin. Lea and Febiger, Philadelphia.

Taggart, P., Gibbons, D., and Somerville, W. (1969). Some effects of motor car driving on the normal and abnormal heart. British Medical fournal, 4, 130-134

Requests for reprints to Dr Peter Taggart, Department of Cardiology, The Middlesex Hospital, Mortimer Street, London W1. 